Article

\title{
Investigation of Heat Generation from Biomass Fuels
}

\author{
Naoharu Murasawa * and Hiroshi Koseki \\ Chiba Institute of Science, 3 Shiomi-cho, Choshi Chiba 288-0025, Japan; E-Mail: koseki@fri.go.jp \\ * Author to whom correspondence should be addressed; E-Mail: n-murasawa@cis.ac.jp; \\ Tel.: +81-479-30-4500.
}

Academic Editor: Thomas E. Amidon

Received: 10 March 2015 / Accepted: 22 May 2015 / Published: 2 June 2015

\begin{abstract}
New biomass fuels are constantly being developed from renewable resources in an effort to counter global warming and to create a sustainable society based on recycling. Among these, biomass fuels manufactured from waste are prone to microbial fermentation, and are likely to cause fires and explosions if safety measures, including sufficient risk assessments and long-term storage, are not considered. In this study, we conducted a series of experiments on several types of newly developed biomass fuels, using combinations of various thermal- and gas-analysers, to identify the risks related to heat- and gas-generation. Since a method for the evaluation of the relative risks of biomass fuels is not yet established in Japan, we also such a method based on our experimental results. The present study found that in cases where safety measures are not thoroughly observed, biomass fuels manufactured from waste materials have a higher possibility of combusting spontaneously at the storage site due to microbial fermentation and heat generation.
\end{abstract}

Keywords: biomass fuels; heat generation; fermentation; thermal and gas analysers; risk evaluation method

\section{Introduction}

Japan has become one of the world's heaviest consumers of fossil fuels, which is associated with social development during its period of high economic growth [1]. Today, Japan depends on foreign imports for the majority of its energy resources, including fossil fuels, and there is a need to develop energy supply and power generation methods that will help mitigate global warming [2]. 
Given the accident at the Fukushima Daiichi Nuclear Power Plant that occurred on 11 March 2011 in the aftermath of the Great East Japan Earthquake, existing Japanese energy policies are in particular need of review and revision, giving due consideration to the idea of datsu-genpatsu ("departure from nuclear power") [3]. Since that disaster, an increasing focus has been placed on biomass fuels as an energy source to replace fossil fuels and nuclear energy, and the government of Japan has begun implementing policies designed to encourage their widespread application [4,5].

The development and study of novel biomass fuels are also progressing quickly. However, hastily revising energy policies, shifting towards a recycling-based sustainable society without a long-term evaluation of safety aspects, and embarking too readily on the practical application of newly developed biomass fuels, may trigger another disaster, such as that which occurred at the Refuse-Derived Fuel (RDF) power station in Mie Prefecture, in 2003 [6,7].

It has been demonstrated that biomass fuels manufactured from waste are particularly prone to microbial fermentation [8,9], and these fuels may spontaneously combust due to heat generation from fermentation and oxidation. Moreover, some biomass fuels includes fatty acid esters. Fatty acid esters generate heat through oxidation, which can eventually result in spontaneous ignition during transport or storage. Therefore, we conducted experiments for several newly developed biomass fuels in order to evaluate storage risks and safety measures, using a combination of highly sensitive thermal and gas analysers. Since an evaluation method for the relative risks of biomass fuels has not been established in Japan, this study also aims to investigate such a method, using the experimental values as an index.

\section{Experimental}

\subsection{Samples}

The biomass fuels used in this study include wood pellets (two types), sludge fuel, chicken dung, palm shell fuel, and rice straw pellets. Wood pellets were made from logged trees, which were ground and then formed into pellets for use as fuel in wood stoves [10]. Two types of pellets were used: pellets from tree bark and pellets from tree trunks (Figure 1). Sewage sludge was easily obtained, and its conversion and use as fuel is expected to reduce its disposal costs (Figure 2) [11].

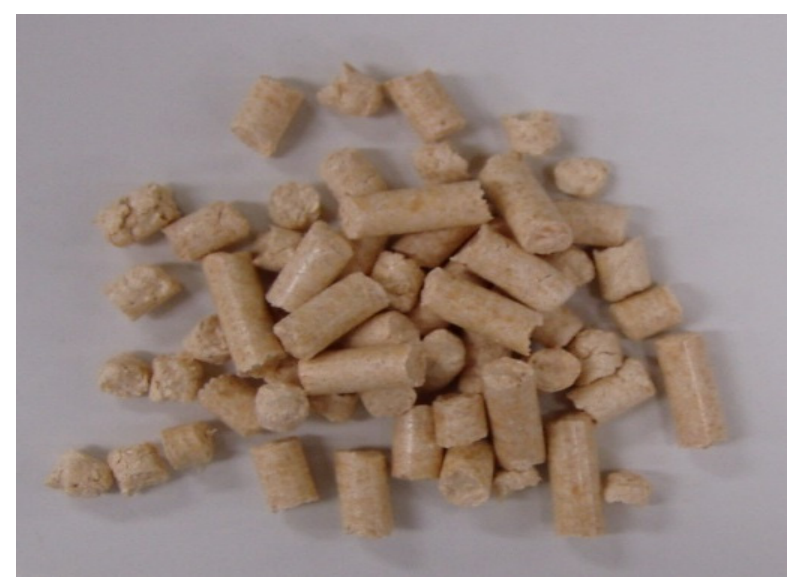

Figure 1. Wood pellets (made from tree trunks). 


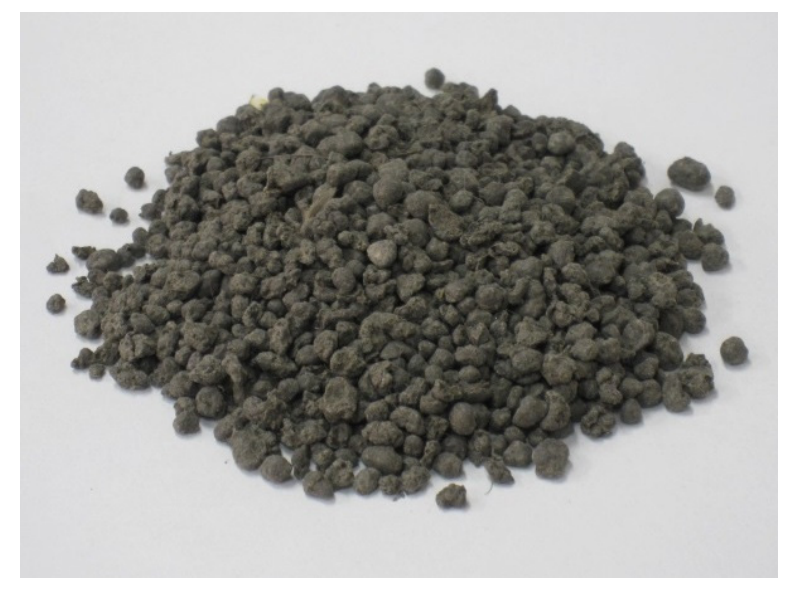

Figure 2. Sludge fuel.

Chicken dung is often used as fuel for boilers and heating equipment on chicken farms. Palm shells were obtained from oil palm residue after the manufacturing of soap and cooking oil [12]. Rice straw pellets were made from rice straw that could no longer be shipped, because of rumours of radioactive contamination due to the Great East Japan Earthquake.

\subsection{Calorimetry}

A Calvet calorimeter (Setaram C80, Lyon, France) was used for additional thermal testing. The C80 is a twin-type highly sensitive heat-flux calorimeter. It can reduce the effects of the vaporization of water contained in the sample by using a high-pressure closed vessel $(8 \mathrm{~mL})$, and can take measurements from room temperature up to $300{ }^{\circ} \mathrm{C}$. Samples $(\sim 1500 \mathrm{mg})$ were analysed in a sealed vessel and the temperature was increased at a rate of $0.1 \mathrm{~K} / \mathrm{min}$ up to $300^{\circ} \mathrm{C}$.

\subsection{High-Sensitivity Isothermal Calorimetry}

To examine in detail the faint heat generation from the fermentation and oxidation of fatty acid esters, we used a highly sensitive isothermal calorimeter (Thermometric TAM-III, Jarfalla, Sweden). The TAM (Figure 3) can measure the nanoscale amount of heat generated by microbial fermentation.

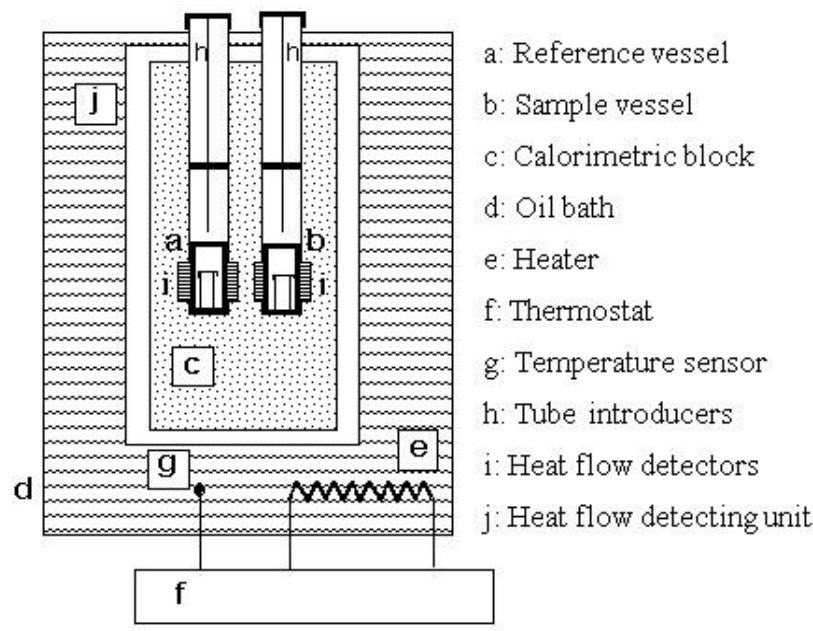

Figure 3. Schematic diagram of TAM-III thermometric calorimeter. 
Analysis was performed by sealing $\sim 1000 \mathrm{mg}$ of the sample in a $4-\mathrm{mL}$ container, maintained at $50{ }^{\circ} \mathrm{C}$ for three days.

\subsection{Gas Chromatography}

To study gas emissions during storage, samples of approximately 50 g were placed in a $1 \mathrm{~L}$ glass bottle that was sealed airtight and placed in a thermostatically controlled oven. The resulting gas was collected and measured by gas chromatography (GC-14B, Shimadzu, Japan) using a standard gas (carbon monoxide (CO): 0.05\%, ethane $\left(\mathrm{C}_{2} \mathrm{H}_{6}\right): 0.995 \%$, hydrogen $\left(\mathrm{H}_{2}\right): 0.097 \%$, carbon dioxide $\left(\mathrm{CO}_{2}\right)$ : $0.996 \%$, methane $\left.\left(\mathrm{CH}_{4}\right): 0.987 \%\right)$ for calibration, and a thermal conductivity detector (TCD) $\left(200{ }^{\circ} \mathrm{C}\right.$, $50 \mathrm{~mA}$ sensitivity, $20 \mathrm{~mL} / \mathrm{min} \mathrm{Ar}$ carrier gas). The column temperature ranged from $40{ }^{\circ} \mathrm{C}$ (6 min hold) to $80{ }^{\circ} \mathrm{C}$ (12 min hold) to $150{ }^{\circ} \mathrm{C}$ (10 min hold), and was increased at a rate of $40{ }^{\circ} \mathrm{C} / \mathrm{min}$. An air cylinder (oxygen $\left(\mathrm{O}_{2}\right): 21 \%$, nitrogen $\left(\mathrm{N}_{2}\right): 79 \%$ ) was used as the standard gas for measurement of $\mathrm{O}_{2}$ and $\mathrm{N}_{2}$. For these measurements, we used a TCD $\left(200^{\circ} \mathrm{C}, 30 \mathrm{~mA}\right.$ sensitivity, $20 \mathrm{~mL} / \mathrm{min}$ Ar carrier gas $)$ with the isothermal column temperature maintained at $30^{\circ} \mathrm{C}$.

\section{Results and Discussion}

\subsection{Calorimetry}

Figures 4-9 show the C80 calorimetry results of the various fuel samples prepared without and with the addition of distilled water (equal to $20 \%$ of the sample). Distilled water was added to the samples in order to examine the effect of moisture content on heat generation. Table 1 summarises the exothermic onset temperatures of each sample. The exothermic onset temperature was taken as the temperature at which the rate of heat generation increased to $0.005 \mathrm{~mW}$.

Table 1. Heat-generation onset temperatures of various biomass fuels, as determined by $\mathrm{C} 80$ calorimetry.

\begin{tabular}{cc}
\hline Sample & Heat generation onset temperature $\left({ }^{\circ} \mathbf{C}\right)$ \\
\hline Wood pellets (made from tree bark) & 59.3 \\
Wood pellets (made from tree bark) + distilled water 20\% & 48.3 \\
Wood pellets (made from tree trunks) & 64.3 \\
Wood pellets (made from tree trunks) + distilled water 20\% & 56.2 \\
Sludge fuel & 42.1 \\
Sludge fuel + distilled water 20\% & 26.3 \\
Chicken dung & 28.5 \\
Chicken dung + distilled water 20\% & 26.1 \\
Palm shell fuel & 90.7 \\
Palm shell fuel + distilled water 20\% & 26.3 \\
Rice straw pellets & 52.3 \\
Rice straw pellets + distilled water 20\% & 48.5 \\
\hline
\end{tabular}




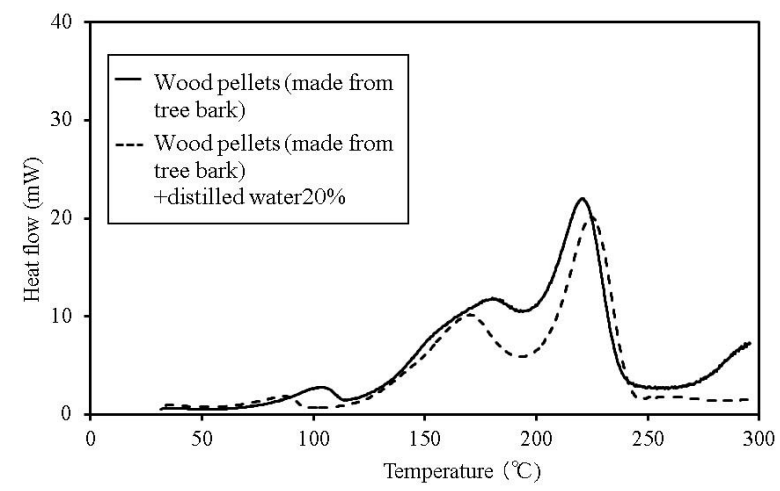

Figure 4. C80 calorimetry curves for wood pellets (made from tree bark).

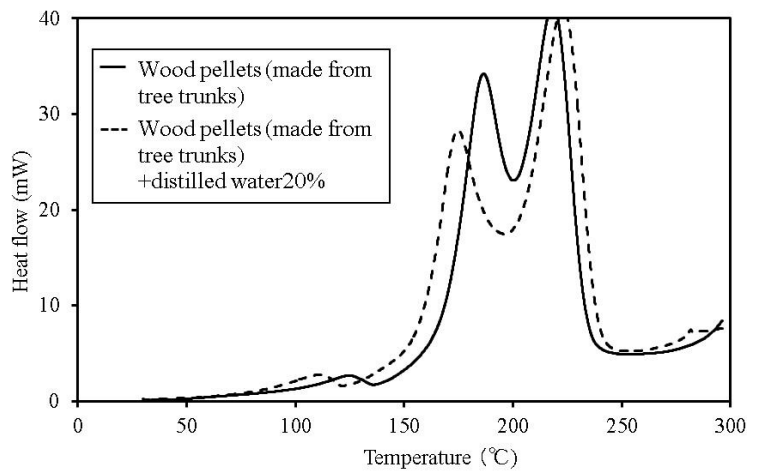

Figure 5. C80 calorimetry curves for wood pellets (made from tree trunks).

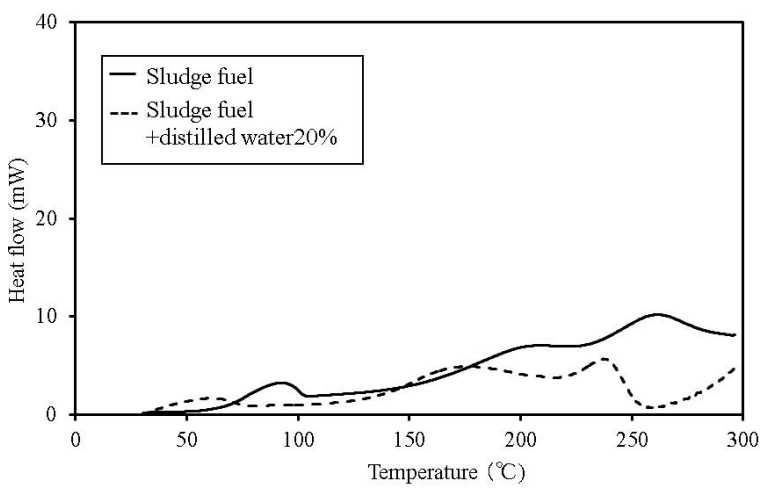

Figure 6. C80 calorimetry curves for sludge fuel.

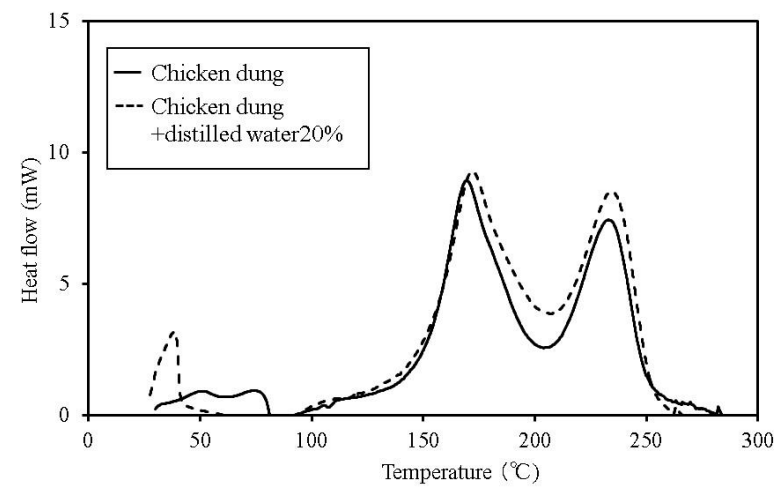

Figure 7. C80 calorimetry curves for chicken dung. 


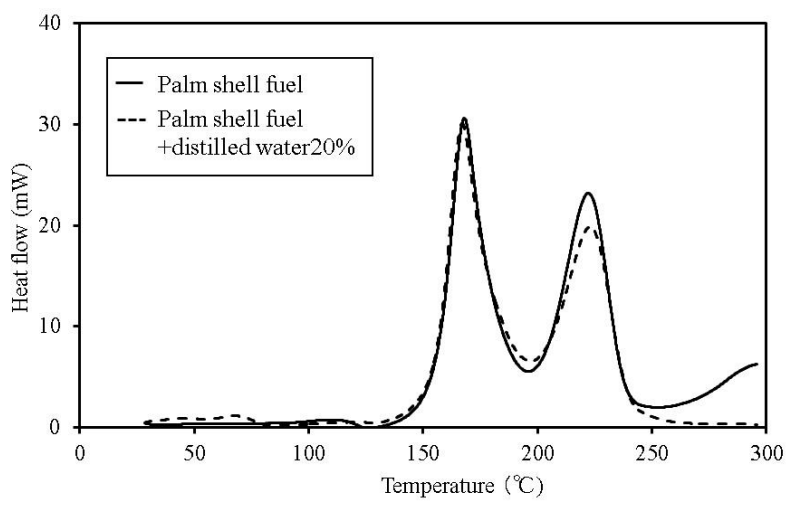

Figure 8. C80 calorimetry curves for palm shell fuel.

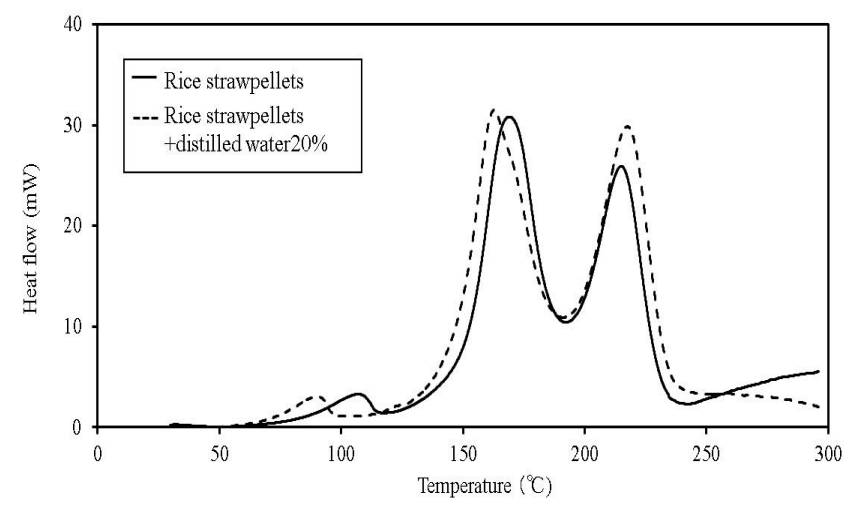

Figure 9. C80 calorimetry curves for rice straw pellets.

The temperature at which faint heat generation begins is lower in all of the samples with distilled water, compared to their counterparts without the added water. Heat generation over a temperature range of $80-100{ }^{\circ} \mathrm{C}$ is expected to be caused by the fatty acid esters contained in all the samples [13]. For temperatures above this range, the heat generation is expected to be caused by decomposition $[14,15]$. The start of faint heat generation after adding moisture is expected to be caused by fermentation, and is observed in the sludge fuel and chicken dung almost immediately, even at temperatures of $30^{\circ} \mathrm{C}$ or less.

The process of heat generation leading to spontaneous ignition of these items begins with a small amount of heat generated from fermentation as a result of microbial activity. Next, the fatty acid esters contained within the items begin to oxidise as the temperature gradually rises. Even if the microorganisms die, the temperature continues to rise and ultimately results in spontaneous ignition.

Based on the $\mathrm{C} 80$ calorimetry results, it is desirable to incorporate the following safety measures. First, if the internal temperature of the biomass fuel is between $30-50{ }^{\circ} \mathrm{C}$, fermentation begins. Only faint heat is generated from fermentation and breaking down the pile. Conducting a heat dissipation treatment at this stage lowers the possibility of a further increase in temperature, which could lead to spontaneous ignition.

Second, if the internal temperature of the biomass fuel is between $50-80{ }^{\circ} \mathrm{C}$, fermentation, continues and oxidation of the fatty acid esters produced by fermentation, occurs. Self-heating is already in progress at this stage and immediate evasive action is required. At this point, breaking down the pile increases the oxygen supply to the area of self-heating, rapidly increasing the temperature and the possibility of combustion. The amount of heat generated by these reactions is larger than that caused by fermentation. 
Venting inactive gas as needed is the recommended action. If water is sprayed onto the biomass fuel with the purpose of reducing its temperature, particular attention must be paid to preventing subsequent fermentation.

\subsection{Highly Sensitive Isothermal Calorimeter}

The TAM-III calorimeter can measure the change in activity of microorganisms over time. Figures 10-15 show the TAM-III calorimetry curves of the various fuel samples prepared without and with the addition of distilled water (equal to $20 \%(\mathrm{w} / \mathrm{w})$ of the sample), and Table 2 summarizes the amount of heat generated. Heat generation has been considered for two periods: 0-24 h, and 24-72 h. In addition, heat generation was considered for a combination of both time periods. The TAM-III temperature was held at $50{ }^{\circ} \mathrm{C}$ for all tests, because microbial activity occurs most vigorously in this temperature range but becomes inactive at higher temperatures $[16,17]$.

Table 2. Heat generation of various biomass fuels, as determined by TAM calorimetry at $50{ }^{\circ} \mathrm{C}$ (untreated samples).

\begin{tabular}{cccc}
\hline Sample & $\begin{array}{c}\text { Heat generation } \\
(\mathbf{J} / \mathbf{g}) \mathbf{0}-\mathbf{2 4} \mathbf{~ h}\end{array}$ & $\begin{array}{c}\text { Heat generation } \\
(\mathbf{J} / \mathbf{g}) \mathbf{2 4}-\mathbf{7 2} \mathbf{~ h}\end{array}$ & $\begin{array}{c}\text { Heat generation } \\
(\mathbf{J} / \mathbf{g}) \mathbf{0}-\mathbf{7 2} \mathbf{~ h}\end{array}$ \\
\hline $\begin{array}{c}\text { Wood pellets (made from tree bark) } \\
\text { Wood pellets (made from tree bark) }+\end{array}$ & 1.27 & 1.59 & 2.85 \\
distilled water 20\% & 7.95 & 10.36 & 18.31 \\
Wood pellets (made from tree trunks) & 1.74 & 1.96 & 3.71 \\
Wood pellets (made from tree trunks) & & & \\
distilled water 20\% & 10.11 & 2.86 & 12.97 \\
Sludge fuel & 17.74 & $11.14 *$ & $28.88 * *$ \\
Sludge fuel + distilled water 20\% & 35.11 & 8.52 & 43.63 \\
Chicken dung & 3.67 & 5.68 & 9.35 \\
Chicken dung + distilled water 20\% & 80.38 & $96.82 *$ & $177.2 * *$ \\
Palm shell fuel & 1.06 & 1.00 & 2.07 \\
Palm shell fuel + distilled water 20\% & 8.96 & 6.14 & 15.10 \\
Rice straw pellets & 1.53 & 2.08 & 3.61 \\
Rice straw pellets + distilled water 20\% & 8.24 & 6.58 & 14.82 \\
\hline
\end{tabular}

*24-64 h; **0-64 h.

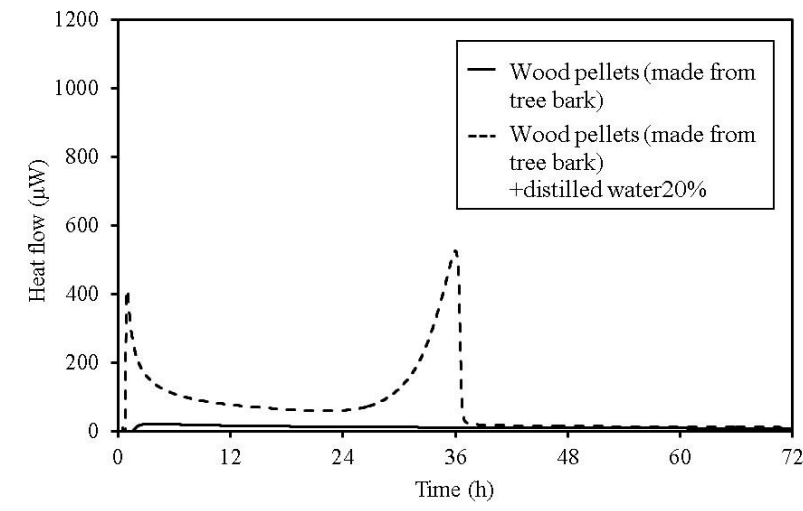

Figure 10. TAM calorimetry curves for wood pellets (made from tree bark). 


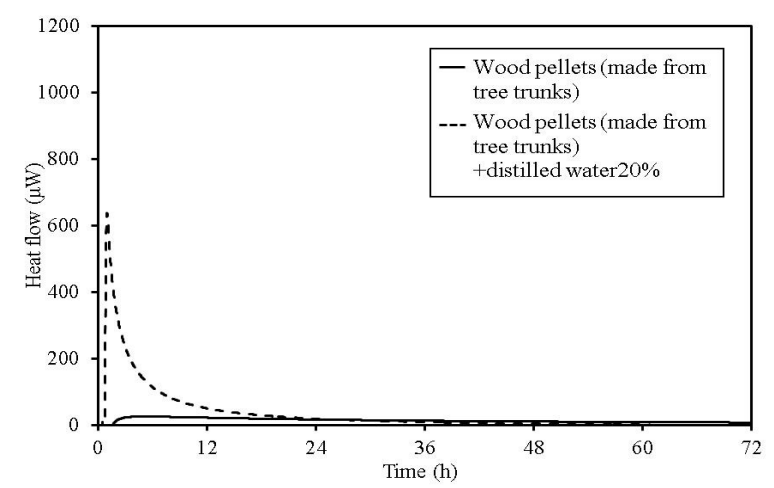

Figure 11. TAM calorimetry curves for wood pellets (made from tree trunks).

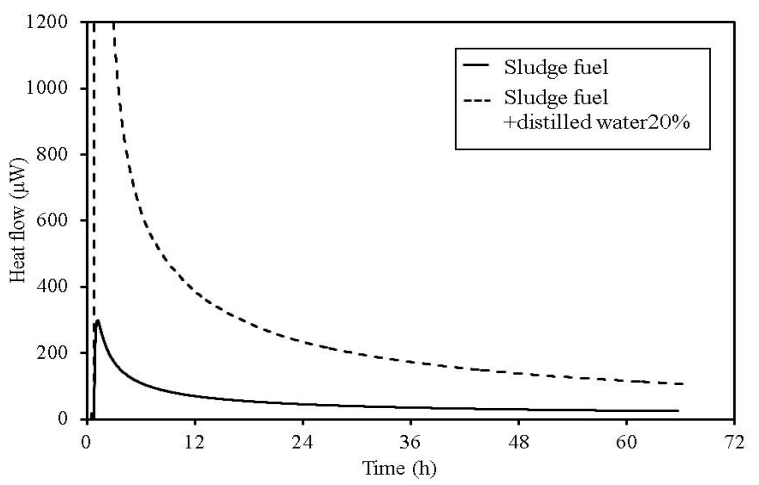

Figure 12. TAM calorimetry curves for sludge fuel.

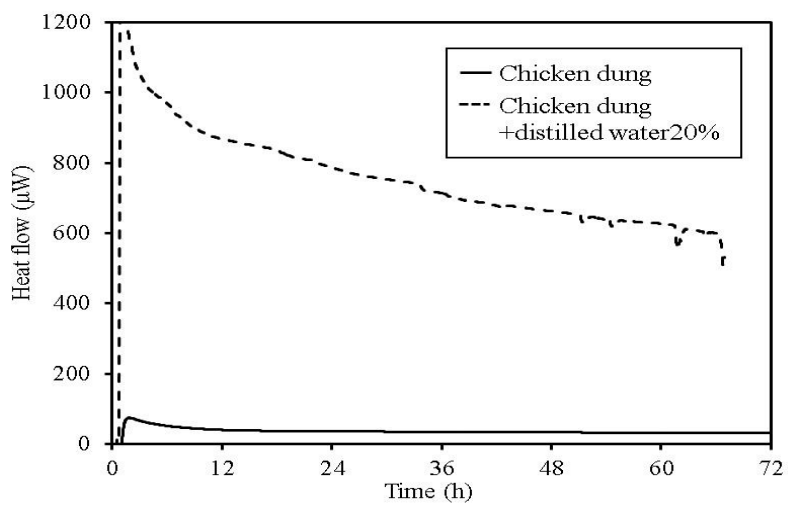

Figure 13. TAM calorimetry curves for chicken dung.

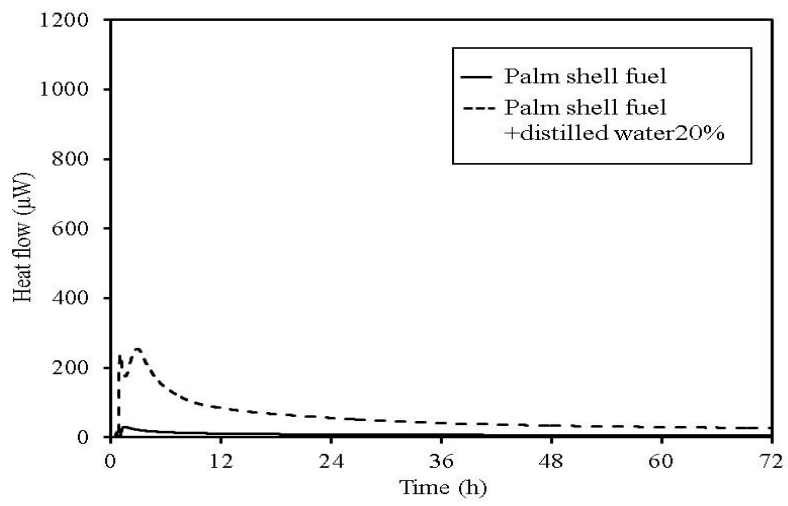

Figure 14. TAM calorimetry curves for palm shell fuel. 


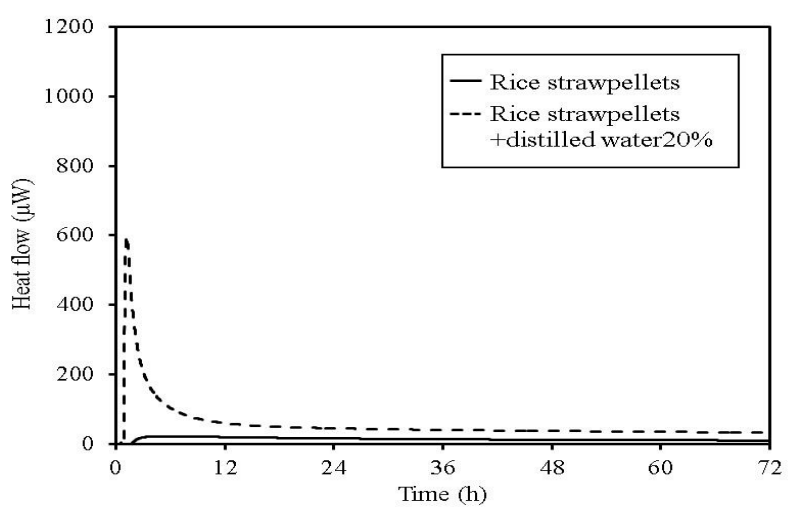

Figure 15. TAM calorimetry curves for rice straw pellets.

Considering the thermal behaviour of wood pellets (made from tree bark), once distilled water is added, heat generation begins immediately and increases again after $24 \mathrm{~h}$. This is assumed to occur because microorganism activity increases over a period of time. Once oxygen in the sealed sample container is consumed by rapid fermentation, the reaction becomes inactive.

In wood pellets (made from tree trunks), similar to those made from tree bark, an increase in heat generation is observed when distilled water is added. However, the two-phase heat generation that occurs for the wood pellets made from bark, is not observed.

Furthermore, in sludge fuel, chicken dung and palm shell fuel, an increase in heat generation associated with the addition of distilled water is observed. The heat generated by chicken dung increases by approximately 19 times when distilled water is added. Sludge fuel and chicken dung are made from faecal matter, and are more likely to contain a large number of microorganisms, which are assumed to become active with the addition of distilled water.

\subsection{Gas Chromatography}

In regards to the risks related to the storage of biomass fuels, confirmation of the release of flammable gases such as $\mathrm{H}_{2}, \mathrm{CH}_{4}$, and $\mathrm{CO}$ is important. There have been cases in which waste in a waste disposer has fermented, filling the environment with flammable gases and causing an explosion [18]. Additionally, there have been cases in which active fermentation has occurred in a storage location, releasing a large amount of $\mathrm{CO}_{2}$, which resulted in the death of workers due to asphyxiation [19].

The GC analysis results of the various fuel samples are shown in Table 3. There is an increase in the amount of $\mathrm{CO}_{2}$ generated in all samples when distilled water is added. $\mathrm{H}_{2}$ generation is also observed, likely due to the high possibility of anaerobic fermentation, in addition to aerobic fermentation [20]. $\mathrm{CO}$ and $\mathrm{CH}_{4}$, however, are not detected according to the measurement conditions at the time. 
Table 3. GC results for untreated samples of various biomass fuels $\left(25^{\circ} \mathrm{C}\right)$.

\begin{tabular}{|c|c|c|c|c|c|c|c|c|}
\hline \multirow{2}{*}{ Sample } & \multirow{2}{*}{$\begin{array}{l}\text { Storage } \\
\text { period }\end{array}$} & \multirow{2}{*}{$\begin{array}{c}\text { Storage } \\
\text { temperature }\end{array}$} & \multicolumn{6}{|c|}{ GC results \% } \\
\hline & & & $\mathbf{O}_{2}$ & $\mathbf{N}_{2}$ & $\mathbf{H}_{2}$ & $\mathrm{CO}$ & $\mathrm{CH}_{4}$ & $\mathrm{CO}_{2}$ \\
\hline Wood pellets (made from tree bark) & \multirow{12}{*}{10 days } & \multirow{12}{*}{$25^{\circ} \mathrm{C}$} & 19.55 & 76.97 & 0.0014 & - & - & 0.70 \\
\hline $\begin{array}{l}\text { Wood pellets (made from tree bark) }+ \\
\text { distilled water } 20 \%\end{array}$ & & & 1.37 & 68.87 & 0.014 & - & - & 21.67 \\
\hline Wood pellets (made from tree trunks) & & & 20.67 & 77.23 & 0.002 & - & - & 0.08 \\
\hline $\begin{array}{l}\text { Wood pellets (made from tree trunks) }+ \\
\text { distilled water } 20 \%\end{array}$ & & & 17.88 & 78.53 & 0.0047 & - & - & 1.94 \\
\hline Sludge fuel & & & 19.47 & 77.32 & - & - & - & 0.49 \\
\hline Sludge fuel + distilled water $20 \%$ & & & 17.24 & 76.22 & - & - & - & 2.29 \\
\hline Chicken dung & & & 9.53 & 70.12 & - & - & - & 14.20 \\
\hline Chicken dung + distilled water $20 \%$ & & & 1.48 & 73.76 & 0.27 & - & - & 21.99 \\
\hline Palm shell fuel & & & 20.46 & 76.13 & - & - & - & 0.06 \\
\hline Palm shell fuel + distilled water $20 \%$ & & & 19,86 & 78.32 & - & - & - & 3.07 \\
\hline Rice straw pellets & & & 20.57 & 76.39 & - & - & - & 0.04 \\
\hline Rice straw pellets + distilled water $20 \%$ & & & 2.17 & 75.69 & 0.0031 & - & - & 16.93 \\
\hline
\end{tabular}

In wood pellets (made from tree bark), a large increase in $\mathrm{CO}_{2}$ is observed with the addition of moisture. In chicken dung, high generation of $\mathrm{CO}_{2}$ is observed irrespective of the addition of distilled water. Considering its thermal behaviour, chicken dung is assumed to contain more moisture than the wood pellets, and therefore believed to be more conducive to fermentation. Other samples may also contain microorganisms, but these samples do not have enough moisture for microorganisms to become active, so fermentation is assumed difficult under normal conditions. However, when the amount of contained moisture is increased by some factor, fermentation is assumed to occur, leading to a temperature increase and spontaneous ignition.

Under normal conditions, even if flammable gas and $\mathrm{CO}_{2}$ are released, they are diffused in the air and their concentration decreases, so the risk from these gases is lower. However, when biomass fuel that is likely to ferment is transported in a tightly sealed container, or stored for a long period in a silo, caution is required to avoid ignition and explosion. Measuring the generated gas using a gas detection tube is recommended, in addition to temperature monitoring and regular confirmation of whether fermentation is occurring or flammable gases are being generated.

\section{Mechanism of the Fire}

Based on the above results, we propose a mechanism of the fire with the following steps (Figure 16). The first step occurs at $20-50{ }^{\circ} \mathrm{C}$, as observed from the C80 calorimetry curves (Figures 4-9). When the temperature increases to $60-80{ }^{\circ} \mathrm{C}$, most of the microorganisms die from the heat, which greatly inhibits aerobic heat generation. The addition of water promotes microbial activity, as seen in the TAM data (Figures 10-15) and Table 3, where sample temperatures are maintained at $50{ }^{\circ} \mathrm{C}$.

Moreover, microorganisms require optimum moisture content and cannot become active when the moisture is too low or too high [20]. Our previous studies on heat generation of RDF and wood chips [13] support these results. Generated heat accumulates up to $100^{\circ} \mathrm{C}$, after which the water content vaporises 
and the second stage of the process occurs. Fatty acid esters are present in plants, and may be oxidised, producing peroxide. In the third step, cellulose and other organic materials begin to burn [21].

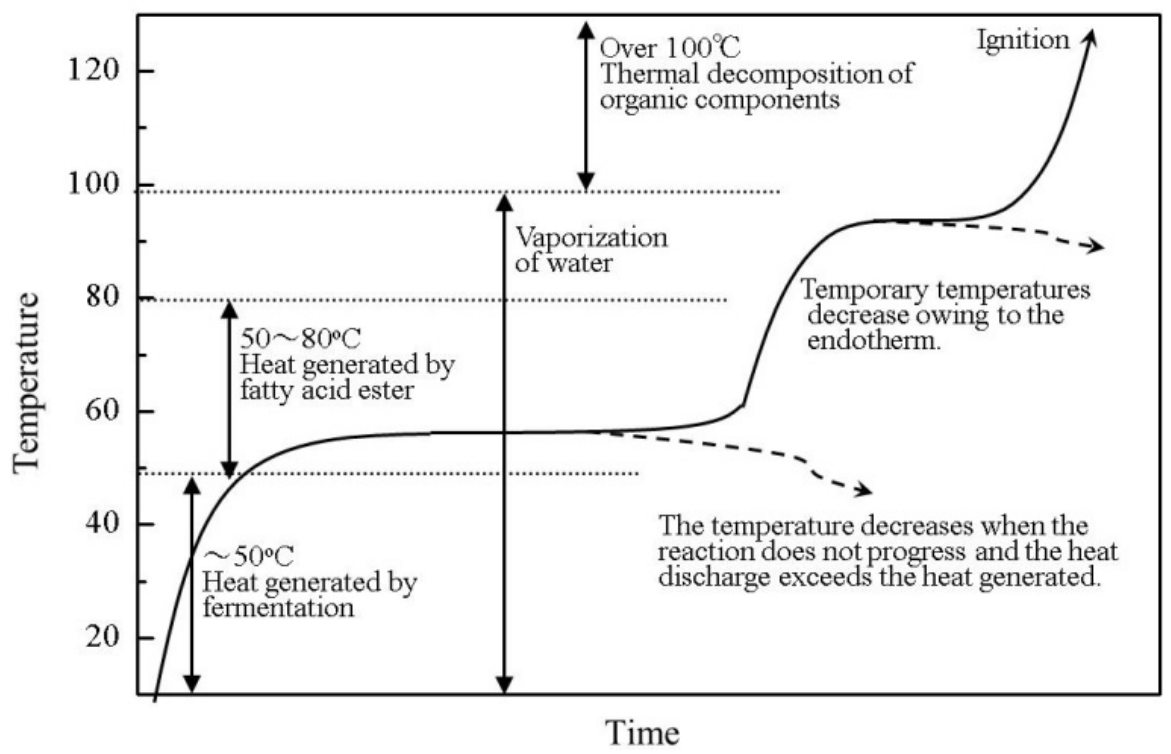

Figure 16. Combustion mechanism of biomass fuels.

\section{Risk Ranking of Biomass Fuels}

A number of methods exist that can be used to estimate the risks involved with large piles of biomass fuels, based on experimental results. For example, the formulae established by Frank-Kamenetskii [22] and Semenov [23] can be used to estimate the critical ignition temperature, and therefore the risk of natural ignition presented by piled materials. Although such methods allow for the assumption of a critical ignition temperature relative to the height of the pile, it is not possible to clarify which of the articles contained in the pile present an increased risk of ignition.

It is important to identify materials that are most likely to generate heat and trigger a spontaneous ignition. To examine the feasibility of a new risk assessment method, we focussed on identifying materials that are likely to generate heat, based on the values obtained from our experiments. An attempt was made to evaluate the relative risk using the results for exothermic onset temperature $(\mathrm{C} 80)$, amount of heat generated (TAM), and the amount of combustible gases generated (GC) as indices. This method was used to evaluate the simple progression of microbial fermentation. The "exothermic onset temperature" (Tonset) indicates how easily exothermal reactions occur, whereas the "amount of heat generated" (Q) indicates the scale of generated heat.

The temperature at which heat generation begins was determined using the $\mathrm{C} 80$ calorimetry results; a higher score represents a greater possibility of heat generation at a lower temperature, and therefore greater associated risk. The temperature at which heat generation begins was allocated a score according to the $\mathrm{C} 80$ calorimetry results (see Table 3). Circled numbers show risk ranking.

$$
0{ }^{\circ} \mathrm{C} \leq \text { (5) }<30{ }^{\circ} \mathrm{C} \leq \text { (4) }<60{ }^{\circ} \mathrm{C} \leq \text { (3) } \leq 90^{\circ} \mathrm{C} \leq \text { (2) }<120^{\circ} \mathrm{C} \leq \text { (1) }<150{ }^{\circ} \mathrm{C}
$$

The amount of heat generated immediately after the onset of TAM measurements at $50{ }^{\circ} \mathrm{C}$, and the amount up to $72 \mathrm{~h}$ later was summed to give the total heat generation. The relative risk of heat generation 
in each sample was scored on the basis of the following standard, in which a higher score represents greater heat generation and a higher risk. The score for heat generation was based on the TAM results (see Table 4).

$$
0 \mathrm{~J} / \mathrm{g} \leq \text { (1) }<10 \mathrm{~J} / \mathrm{g} \leq \text { (2) }<20 \mathrm{~J} / \mathrm{g} \leq \text { (3) }<30 \mathrm{~J} / \mathrm{g} \leq \text { (4) }<40 \mathrm{~J} / \mathrm{g} \leq \text { (5) }<50 \mathrm{~J} / \mathrm{g} \leq \text { (6) }<60 \mathrm{~J} / \mathrm{g}
$$

Risk for flammable gases is derived directly from their concentration. Consider a mixture of flammable gases and air, in which the percentages of flammable gases are $n, n^{\prime}, n^{\prime \prime} \ldots$, and their limits are $\mathrm{N}, \mathrm{N}^{\prime}, \mathrm{N}^{\prime \prime} \ldots$, respectively Le Chatelier [24,25] proposed the following rule: the flammability limit of the complex mixture occurs at percentages n, $n^{\prime}$ and $n^{\prime \prime}$, such that:

$$
\frac{n}{N}+\frac{n^{\prime}}{N^{\prime}}+\frac{n^{\prime \prime}}{N^{\prime \prime}}+\cdots=1
$$

The rule can be justified according to Le Chatelier's principle in the following way: it is more or less obvious that if two mixtures $(\mathrm{G}+$ air $)$ and $\left(\mathrm{G}^{\prime}+\right.$ air $)$ combine to form a homogeneous mixture, then the latter will propagate a flame if both initial mixtures support propagation. It will not propagate a flame if both initial mixtures are either below the lower limit or above the upper limit. The result is a mixture in which $\mathrm{G}$ and $\mathrm{G}^{\prime}$ are present in percentages, $\mathrm{n}$ and $\mathrm{n}^{\prime}$, such that:

$$
\frac{n}{N}+\frac{n^{\prime}}{N^{\prime}}=1
$$

is at the propagation limit (lower or upper, depending on whether $\mathrm{N}$ and $\mathrm{N}^{\prime}$ are relative to the individual lower or upper limits). The argument can be easily extended to other gases, and leads to Equation (3).

The risk for the generation of flammable gases is therefore calculated by combining the concentrations of all evolved flammable gases such as $\mathrm{H}_{2}, \mathrm{CO}$ and $\mathrm{CH}_{4}$, as detected by the $\mathrm{GC}$, and comparing these with their lower explosion limit (4.0\% for $\mathrm{H}_{2}, 12.5 \%$ for $\mathrm{CO}$ and $5.0 \%$ for $\mathrm{CH}_{4}$ ) [26]. Moreover, the risk can be greater if a gas concentration exceed the its higher explosion limit although the risk is low. In order to compare the risk of flammable gas generation in each sample, the score was based on Equation (5). This calculation excludes the effect of $\mathrm{CO}_{2}$ :

$$
\text { Rank for evolution of flammable gases }=\frac{\left[\mathrm{H}_{2}\right]}{4.0 \%}+\frac{[\mathrm{CO}]}{12.5 \%}+\frac{\left[\mathrm{CH}_{4}\right]}{5.0 \%}
$$

The score for the generation of flammable gases was calculated according to the GC results (see Table 3), giving:

$$
0 \% \leqq \text { (1) }<0.001 \% \leqq(2)<0.01 \% \leqq(3)<0.1 \% \leqq(4)<1 \% \leqq(5)<10 \%
$$

Tables 4 (without added moisture) and 5 (with added moisture) show the relative risks associated with the biomass fuels, as evaluated by the methods discussed above. Figures 17 and 18 show the results from Tables 4 and 5, respectively. The size of the circle represents the "heat-generation amount risk" on the vertical axis, and "heat-generation starting temperature risk" on the horizontal axis. The figures show that the thermal risk increases towards the upper-right corner of the plots. The risk of generating combustible gas also increases as the size of the circle becomes larger. Measured RDF values were also used as a reference for the same thermal hazard evaluation method [8].

Overall, chicken dung, sludge fuel and palm shell fuels may generate heat even when the temperature is below $30^{\circ} \mathrm{C}$. Moreover, the addition of water increases the amount of generated heat, further raising the risk of combustible gas generation. With the other samples, the addition of moisture lowers the 
temperature at which heat generation starts, but the amount of generated heat, and the risk of combustible gas generation are not as high as those for chicken dung, and sludge fuel.

Table 4. Risk ranking of the tested samples.

\begin{tabular}{ccccc}
\hline \multirow{2}{*}{ Sample name } & \multicolumn{2}{c}{ Thermal risk } & & Flammable gas risk \\
\cline { 2 - 3 } & $\mathbf{T}_{\text {onset }}(\mathbf{C 8 0})$ & $\mathbf{Q}$ (TAM) & & $\mathbf{2 5} \pm \mathbf{5}^{\circ} \mathbf{C}(\mathbf{G C})$ \\
\hline Wood pellets (made from tree bark) & 4 & 1 & \\
Wood pellets (made from tree trunks) & 3 & 1 & 1 \\
Sludge fuel & 4 & 3 & 1 \\
Chicken dung & 5 & 1 & 1 \\
Palm shell fuel & 2 & 1 & 1 \\
Rice straw pellets & 4 & 1 & 1 \\
\hline
\end{tabular}

Table 5. Risk ranking of the tested samples + distilled water $20 \%$.

\begin{tabular}{ccccc}
\hline Sample name & \multicolumn{2}{c}{ Thermal risk } & & Flammable gas risk \\
\cline { 2 - 3 } & $\mathbf{T}_{\text {onset }}$ (C80) & $\mathbf{Q}$ (TAM) & & $\mathbf{2 5 \pm \mathbf { 5 } ^ { \circ } \mathbf { C } \text { (GC) }}$ \\
\hline Wood pellets (made from tree bark) + distilled water 20\% & 4 & 2 & 2 \\
Wood pellets (made from tree trunks) + distilled water 20\% & 4 & 2 & 2 \\
Sludge fuel + distilled water 20\% & 5 & 5 & 1 \\
Chicken dung + distilled water 20\% & 5 & 6 & 3 \\
Palm shell fuel + distilled water 20\% & 5 & 2 & 1 \\
Rice straw pellets + distilled water 20\% & 4 & 2 & 2 \\
\hline
\end{tabular}

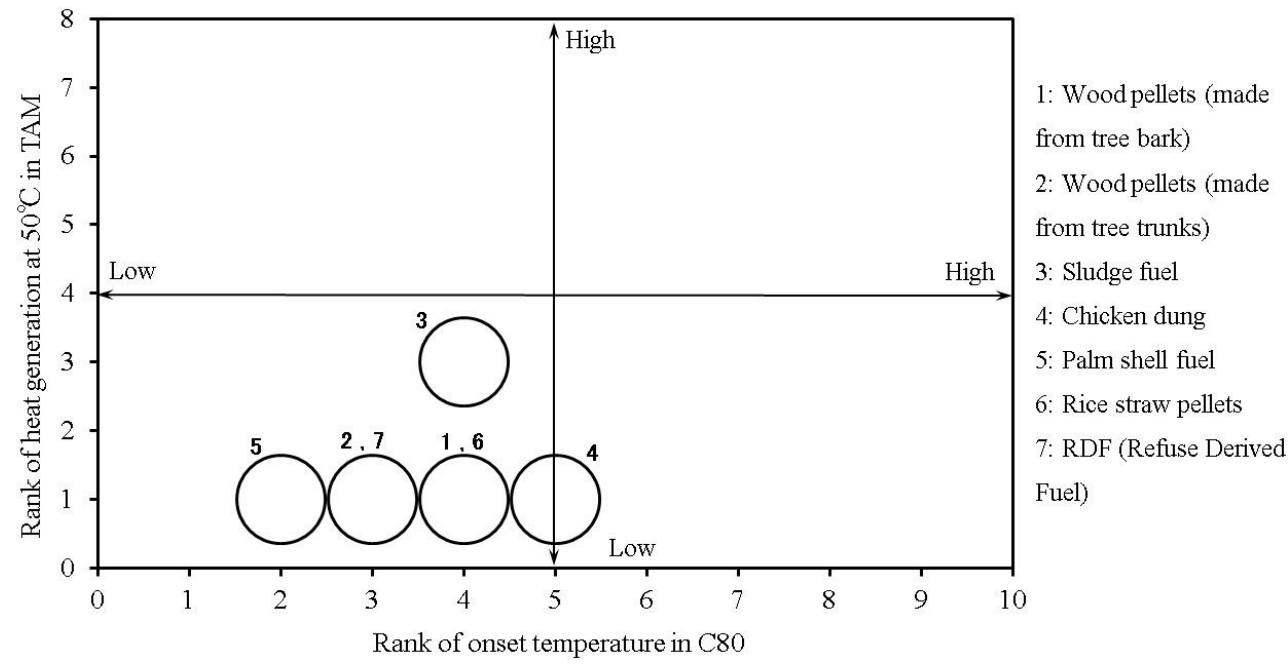

Figure 17. Comparison of risks for onset temperature, heat generation, and flammable gas generation for biomass fuels.

The RDF values reveal that the addition of moisture increases each risk value in the same manner as with poultry manure, and bio-solid fuels. The results also indicate that adding moisture increases the potential for "thermal risk" or "flammable gas risk". This method is assumed to be effective in confirming heat generation that can trigger spontaneous ignition, and in determining the associated risk. Sensitive thermal- and gas-analysis equipment is first used to determine whether minute levels of heat or flammable gas are generated, which may trigger spontaneous ignition. 


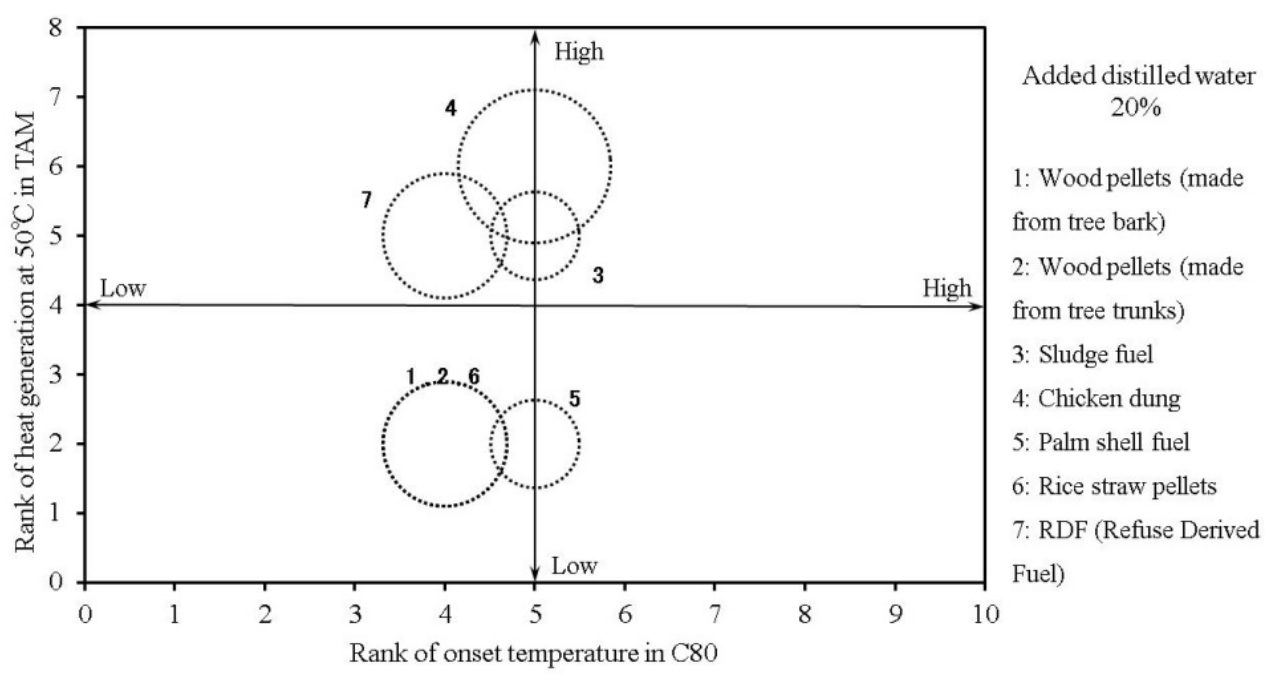

Figure 18. Comparison of risks for onset temperature, heat generation, and flammable gas generation for biomass fuels + distilled water $20 \%$.

Next, for samples with higher risk, the possibility of an increase in temperature by minute heat generation under more adiabatic conditions is considered. Moreover, for samples with higher ignition temperature, the sample quantity can be increased and the results studied more closely. This permits estimation of the ignition temperature at a large scale, utilising data obtained by a theoretical method such as the Frank-Kamenetskii [22] method.

Based on the experimental results, the following conclusions were obtained:

(1) The temperature at which heat generation begins is low in all samples when distilled water is added before the measurement. The start of heat generation under these conditions is assumed to be caused by fermentation, which is observed in sludge fuel and chicken dung immediately after the measurements began. Sludge fuel and chicken dung are more likely to generate heat, even at temperatures of $30^{\circ} \mathrm{C}$ or less.

(2) Fermentation begins when the internal temperature of the stored biomass fuel is between $30-50{ }^{\circ} \mathrm{C}$. Only a small amount of heat is generated from fermentation and breaking down the pile. If the internal temperature of the stored biomass fuel is between $50-80{ }^{\circ} \mathrm{C}$, fermentation and oxidation of the fatty acid esters produced by fermentation occurs. Self-heating is already in progress at this stage and immediate evasive is required.

(3) All samples generate a greater amount of heat as a consequence of increased moisture content. This micro-heat generation is the trigger of fires. Moreover, it is believed that moderate moisture content in an item enables better fermentation and generates heat more easily. Sludge fuel and chicken dung, which are both composed of faecal matter, are more likely to contain a large amount of microorganisms, which are assumed to become active with the addition of distilled water.

(4) There is an increase in the amount of $\mathrm{CO}_{2}$ generated when distilled water is added. Under normal conditions, even if flammable gases and $\mathrm{CO}_{2}$ are released, they are diffused in the air and their concentration decreases, so the risk from these gases is low. However, when biomass fuel that is likely to ferment is transported in a tightly sealed container, or stored for a long period in a silo, caution is required to avoid ignition and explosion. 
(5) The risk of at least one of heat generation temperature, heat generation amount, or flammable gas generation increases due to the addition of distilled water. There is a possibility that chicken dung and sludge fuel may generate heat even at $30^{\circ} \mathrm{C}$ or less, and that the amount of heat generated when distilled water is added also increases the risk of generating flammable gases. For other samples, the temperature at which heat generation begins is lowered by adding distilled water, but the amount of heat generated and the risk of flammable gas is not lowered to the same extent as for chicken dung and sludge fuel.

\section{Conflicts of Interest}

The authors declare no conflict of interest.

\section{References}

1. Warr, B.; Ayres, R.; Eisenmenger, N.; Krausmann, F.; Schandl, H. Energy use and economic development: A comparative analysis of useful work supply in Austria, Japan, the United Kingdom and the US during 100 years of economic growth. Ecol. Econ. 2010, 69, 1904-1917.

2. John, G.; Kaya, Y. Greenhouse gas control technologies. In Proceedings of the 6th International Conference on Greenhouse Gas Control Technologies, Kyoto, Japan, 4 October 2002.

3. Portugal, P.J.; Parady, G.T.; Dominguez, B.C. Japan's energy conundrum: Post-Fukushima scenarios from a life cycle perspective. Energy Policy 2014, 67, 104-115.

4. Benjamin, M.; Zhang, C.Q.; Utama, N.A.; Farzaneh, H.; Ishihara, K.N. Analysis of Japan's post-Fukushima energy strategy. Energy Strategy Rev. 2013, 2, 190-198.

5. Seishu, T.; Hirasawa, T. Research Approaches to Sustainable Biomass Systems; Academic Press: Oxford, UK, 2014.

6. Shimizu, Y.; Wakakura, M.; Arai, M. Heat accumulations and fire accidents of waste piles. J. Loss Prev. Process Ind. 2009, 22, 86-90.

7. Yasuhara, A.; Amano, Y.; Shibamoto, T. Investigation of the self-heating and spontaneous ignition of refuse-derived fuel (RDF) during storage. Waste Manag. 2010, 30, 1161-1164.

8. Fu, Z.M.; Li, X.R.; Koseki, H. Heat generation of refuse derived fuel with water. J. Loss Prev. Process Ind. 2005, 18, 27-33.

9. Fu, Z.M.; Koseki, H.; Iwata, Y. Investigation on spontaneous ignition of two kinds of organic material with water. Thermochim. Acta 2006, 440, 68-74.

10. Tabata, T.; Okuda, T. Life cycle assessment of woody biomass energy utilization: Case study in Gifu Prefecture, Japan. Energy 2012, 45, 944-951.

11. Li, X.; Lim, W.; Iwata, Y.; Koseki, H. Thermal behavior of sewage sludge derived fuels. Therm. Sci. 2008, 12, 137-148.

12. Uemura, Y.; Omar, W.N.; Tsutsui, T.; Yusup, S. Torrefaction of oil palm wastes. Fuel 2011, 90, $2585-2591$.

13. Li, X.R.; Koseki, H.; Momota, M. Evaluation of danger from fermentation-induced spontaneous ignition of wood chips. J. Hazard. Mater. 2006, 135, 15-20.

14. Gray, B.F.; Griffiths, J.F.; Hasko, S.M. Spontaneous ignition hazards in stockpiles of cellulosic materials: Criteria for safe storage. J. Chem. Technol. Biotechnol. 1984, 34, 453-463. 
15. Rychlý, J.; Matisová-Rychlá, L.; Lazár, M.; Slovák, K.; Strlič, M.; Kočar, D.; Kolar, J. Thermal oxidation of cellulose investigated by chemiluminescence: The effect of water at temperatures above $100^{\circ} \mathrm{C}$. Carbohydr. Polym. 2004, 58, 301-309.

16. Murasawa, N.; Koseki, H.; Iwata, Y.; Shibata, Y. Determination of spontaneous ignition of SSSR and fish meal during transport and storage. J. Food Res. 2012, 1, 320-329.

17. Murasawa, N.; Koseki, H.; Iwata, Y.; Gao, L. Study on spontaneous ignition of stored food waste to be used for recycling. Fire Mater. 2013, 37, 520-529.

18. Li, X.R.; Koseki, H.; Iwata, Y. Risk assessment on processing facility of raw organic garbage. J. Hazard. Mater. 2008, 154, 38-43.

19. Murasawa, N.; Koseki, H.; Iwata, Y. Lessons learned from accidents of soy sauce squeezing residue-Risks of spontaneous ignition and oxygen deficiency. Loss Prev. Bull. 2012, 224, 14-17.

20. Thauer, R.K.; Jungermann, K.; Decker, K. Energy conservation in chemotrophic anaerobic bacteria. Bacteriol. Rev. 1977, 41, 100-180.

21. Hogland, W.; Marques, M. Physical biological and chemical processes during storage and spontaneous combustion of waste fuel. Resour. Conserv. Recycl. 2003, 40, 53-69.

22. Frank-Kamenetskii, D.A. Diffusion and Heat Transfer in Chemical Kinetics; Plenum Press: New York, NY, USA, 1969; p. 374.

23. Semenov, N.N. Theories of combustion process. J. Phys. 1928, 48, 571-582.

24. Le Chatelier, H. Estimation of firedamp by flammability limits. Ann. Mines 1891, 19, 388-395.

25. Medrard, L.A. Flammability limits of explosive gaseous mixtures. Accid. Explos. 1987, 1, 163-173.

26. Coward, H.F.; Jones, G.W. Limits of Flammability of Gases and Vapours; US Bureau of Mines: Washington, DC, USA, 1965.

(C) 2015 by the authors; licensee MDPI, Basel, Switzerland. This article is an open access article distributed under the terms and conditions of the Creative Commons Attribution license (http://creativecommons.org/licenses/by/4.0/). 